\title{
26353 - EVALUATION OF ADDING TRAMADOL TO LIDOCAINE IN CONTINUOUS SUPRACLAVICULAR BRACHIAL BLOCK
}

\section{Farnad Imani Assistant professor Of Anesthesiology, Valiollah Hassan, Behzad Sadri, Mahmoud-Reza Alebouyeh, Iran University of Medical Sciences, Tehran, TEHRAN, Iran}

INTRODUCTION:

The goal of this study is comparison of adding tramadol to lidocaine in continuous supraclavicular brachial block for upper extremity procedure.

\section{METHODS:}

This study involved 100 patients with ASA physical status I or II undergoing upper extremity procedures under continuous supraclavicular block. After ethical approval, this block was performed by peripheral nerve stimulator, and after desirable muscular responses, catheter for additional injections was indwelt. Patients were randomly allocated in two groups. Group LN $(\mathrm{n}=50)$ received 2\% lidocaine $7 \mathrm{mg} / \mathrm{kg}$ plus $2 \mathrm{ml}$ normal saline, and Group LT $(\mathrm{n}=50)$ received $2 \%$ lidocaine $7 \mathrm{mg} / \mathrm{kg}$ plus $100 \mathrm{mg}(2 \mathrm{ml})$ tramadol. For additional intraoperative analgesia, $2 \%$ lidocaine through catheter, and intravenous sufentanil and midazolam was administrated. Onset and duration of sensory and motor block, total intraoperative drug consumption (lidocaine, sufentanil and midazolam), time to first postoperative analgesic request, complications, and demographic data were recorded.

\section{RESULTS:}

There were no significant differences in subject demographic and clinical data between lidocaine (LN) and lidocaine plus tramadol (LT) groups with respect to age, gender, weight, anesthesia duration, surgical time and complication. Although there was no significant differences in sensory and motor block durations between the LN and LT groups, LT group experienced significantly shorter times to sensory and motor block initiations (11.5 \pm 0.3 and $15.7 \pm 0.3 \mathrm{~min})$ than $\mathrm{LN}$ group (15.5 \pm 0.4 and $19.9 \pm 0.5 \mathrm{~min})$. Also lidocaine total dose was significantly lesser in LT group $(452 \pm 7 \mathrm{mg})$ compared with LN group (626 $\pm 26 \mathrm{mg}$ ). In LT compared to LN group, intraoperative sufentanil (but not midazolam) consumption was significantly lesser ( $7 \pm 0.8 \mathrm{vs} 10.4 \pm 0.7 \mathrm{mcg}$ ), and time to first postoperative analgesic request was significantly greater ( $8.6 \pm 0.25$ vs $6.7 \pm 0.2 \mathrm{hrs})$. Complication rate between two groups was not significant.

\section{DISCUSSION:}

Addition of $100 \mathrm{mg}$ tramadol to $2 \%$ lidocaine for continuous supraclavicular block has faster onset of sensory and motor block, less intraoperative drug requirement, and prolong postoperative analgesia. Duration of sensory and motor block, and complications were not differences.

Keywords: Tramadol, lidocaine, supraclavicular block

Anesth Analg. 2004 Apr;98(4):1172-7, table of contents. 